\title{
Levels of processing: the evolution of a framework
}

\author{
Roberta Ekuni, Leonardo José Vaz and Orlando Francisco Amodeo Bueno \\ Universidade Federal de São Paulo, São Paulo, SP, Brazil
}

\begin{abstract}
Although the levels of processing framework have evolved over its nearly 40 years of existence, the essence of the idea has not changed from the original. The original article published in 1972 suggests that in the encoding stage of a stimulus, there is a series of processing hierarchies ranging from the shallowest level (perceptual processing - the subject initially perceives the physical and sensory characteristics of the stimulus) to the deepest level (semantic processing-related to pattern recognition and extraction of meaning). The depth processing is associated with high levels of retention and long-term memory traces. After extensive research and criticism, the authors added several concepts that aided in a better understanding of levels of processing framework and the items that subjects can recall such as transfer-appropriate processing and robust encoding. However, there are still some gaps in this framework that call for new scientific investigations, ranging from experimental paradigms with lists of words with healthy or pathological conditions subject to neuroimaging studies to confirm, refute or improve the framework. The aim of this article is to review the publications (articles and book chapters) dating from the original article to the present day to better understand the mnemonic process in terms of levels of processing and to highlight some of its contributions. Keywords: levels of processing, memory, cognition.
\end{abstract}

Received 7 October 2011; received in revised form 18 December 2011; accepted 20 December 2011. Available online 29 December 2011

\section{Introduction}

In everyday life, among the many strategies used to remember things are repeating or reading the same content several times and seeking to establish relationships among the information to be stored, for example, by drafting a short story or creating a mental image. But where do these strategies come from? Which ones work? What helps us retrieve the information we want to remember? The aim of this article is to review the literature and answer these questions in terms of levels of processing (LOP), which is a widely used concept in memory studies. According to Tulving (2002), LOP is a framework, not a theory; a framework is much broader and can be more vague than a theory. The article that introduced the term "levels of processing," published by Craik and Lockhart in 1972, is one of the most widely cited cognitive psychology articles in the literature. According to the Web of Science, since the publication of Craik and Lockhart almost 40 years ago, >3,500 articles have cited the original article (accessed July 2011). Richardson-Klavehn, Gardiner, and Ramponi

Roberta Ekuni, Leonardo José Vaz and Orlando Francisco Amodeo Bueno, Department of Psychobiology, Universidade Federal de São Paulo, São Paulo, Brazil. Correspondence regarding this article should be directed to: Dr. Orlando Francisco Amodeo Bueno, Department of PsychobiologyUniversidade Federal de São Paulo Rua Botucatu, 862, $1^{\circ}$. andar-Cep: 04023-062 São Paulo-SP/Brazil. Telephone: +55 11 2149-0155. E-mail: ofabueno@psicobio.epm.br
(2002) noted that few concepts have proven to be as robust as this one. Table 1 shows a summary of the evolution of this framework.

In the original article, Craik and Lockhart (1972) suggest that it is not the intention to memorize something, but the stimulus-encoding process that is important for

Table 1. Summary of the important aspects of evolution of levels of processing framework

\begin{tabular}{llc}
\hline Authors & \multicolumn{1}{c}{ Topic } & Year \\
\hline $\begin{array}{l}\text { Craik \& } \\
\text { Lockhart }\end{array}$ & Introduced the LOP framework & 1972 \\
$\begin{array}{l}\text { Craik \& } \\
\text { Tulving }\end{array}$ & $\begin{array}{l}\text { Experiments exploring the LOP } \\
\text { framework, and showing LOP } \\
\text { effects }\end{array}$ & 1975 \\
& $\begin{array}{l}\text { Introduced the compatibility and } \\
\text { elaboration concept }\end{array}$ & \\
Morris, & $\begin{array}{l}\text { Criticized the LOP framework; } \\
\text { elaborated the transfer- }\end{array}$ & 1977 \\
Fransford \& & $\begin{array}{l}\text { appropriate processing (TAP) } \\
\text { Tulving }\end{array}$ & $\begin{array}{l}\text { TAP is not incompatible with } \\
\text { LOP }\end{array}$ \\
Lockhart \& & $\begin{array}{l}\text { Introduced the term "robust } \\
\text { enconding" }\end{array}$ & 1979 \\
Craik & $\begin{array}{l}\text { Review in which LOP were } \\
\text { analyzed in relation to } \\
\text { neuroimaging and PET scan }\end{array}$ & 2002 \\
\hline
\end{tabular}


future retrieval of the stimulus. For a better understanding of this, we must assume the widely accepted idea that memory consists of three main stages: encoding (acquisition of information), storage (maintenance of the information) and retrieval (use of the information that was stored) (Atkinson \& Shiffrin, 1968).

Craik and Lockhart (1972) stated that in the encoding stage there is a series of processing hierarchies. During the shallower processing level (perceptual processing), the subject initially perceives the physical and sensory characteristics of the stimulus; the deepest level (semantic processing) is related to pattern recognition and extraction of meaning, with a greater emphasis on semantic analysis than in shallow processing. Memory traces are formed as a result of these processes. To direct the different levels or degrees of processing, tasks are employed during encoding that are preferentially oriented to a perceptual or semantic processing of stimuli. Craik (2002) proposed that semantic analysis, i.e., more "deep" processing, is associated with higher levels of retention and long-term memory traces (Figure 1).

The idea of LOP emerged as an attempt to explain the mnemonic system. In 1975, a series of experiments developed by Craik and Tulving explored further the LOP framework. In these experiments, lists of words were shown to the subject; for each list, different guided tasks were adopted to control the "depth" of processing used to encode the words. For example, in shallow processing, the subject answered questions concerning the word's typeface (for example, is the word "HOUSE" written in capital letters?); in intermediate processing, the subject answered questions about rhyme (for example, does the word "house" rhyme with "pencil"?); and in deep processing, the questions were directed toward the word's semantic content (for example, does the word "house" fit into this sentence: "The has a beautiful window"?). The results of the experiments made the authors realize that when the answer of the processing was compatible, for example,

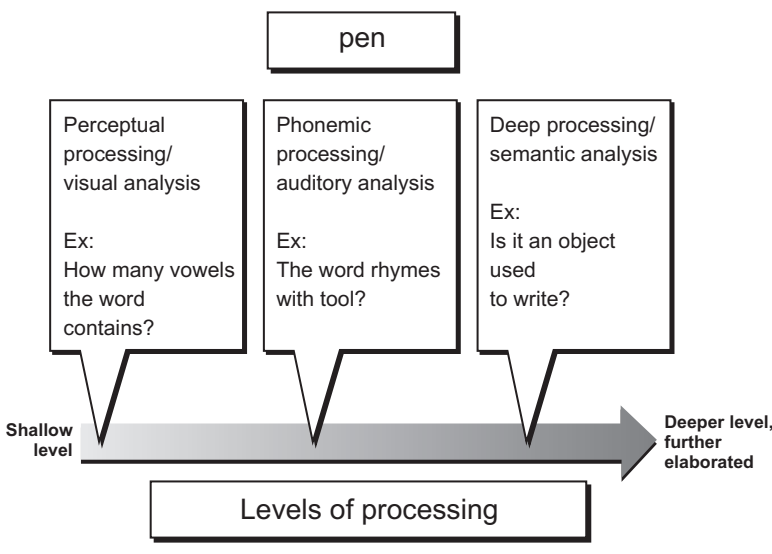

Figure 1. Diagram of levels of processing while encoding the written word "pen" (the subject can analyze it at various levels of processing).
"PEN is an object used to write? - YES", it made the target words be more elaborated and better recalled than with incompatible questions. That concept is known as compatibility (Craik \& Tulving, 1975).

The LOP framework can also be explored using only two levels: shallow and deep processing. For example, in the study by Vaz et al. (manuscript in preparation), a list of the same words was processed differently by two groups of subjects with the help of two concurrent tasks: (a) word appreciation (deep processing - the subject read words aloud as they were displayed on a computer screen and then judged their significance, responding with one of following options: "like", "indifferent" or "dislike", for example, the subject might read the word "letter" and say "like"); (b) counting of closed spaces (shallow processing-in this task, after reading the word aloud, the subject was asked to count the number of closed spaces in the letters that form the word, for example, the word "letter" has two closed spaces, seen in the two letters "e"). The closed spaces counting task required the subjects to focus on the physical or perceptual characteristics of the stimuli while the significance task required them to focus on their meaning. At the end of each list, the subjects were asked to freely recall the words presented. The group who performed the deeper processing task recalled significantly more words than the group who used shallow processing. This result was similar to that observed in other studies (Craik \& Tulving, 1975; Moscovitch \& Craik, 1976; Chalets, Velichkvsky, \& Craik, 1996).

Morris, Bransford, and Franks (1977) showed that semantic processing is better than phonological processing, but only when the retrieval task requires the remembrance of meaning. When the retrieval task requires rhyme recognition, phonological processing gives superior results. For instance, the guided task may be to verify whether the target word fits into the phrase (as in the semantic task " has wings": BIRD; response: "Yes"), or a guided task could be to verify whether the target word rhymes with the preceding word (as in the phonological task "___ rhymes with mat": HAT; response: "Yes"). At the end of the guided task, a memory task is carried out with cues that show only the phrase of the semantic task (so that the subject recalls the target word; for example, BIRD), or only the phrase of the phonetic task (so that the subject recalls the target word; for example, HAT). Thus, if the recall task is congruent with the guided task, the memory is facilitated, even for subjects who perform the shallower, phonetic task. That is, the best processing level is the one that fits the requirements of the retrieval task. Or, in other words, it is better to test what the subject was induced to learn. Following this principle, Morris et al. (1977) proposed an alternative to LOP known as transfer-appropriate processing. This issue, that was 
initially a criticism of LOP, was later added to this framework. Similarly, Tulving (1979) developed the encoding specificity principle, which is an idea that focuses on the compatibility of the cue used in recall with the processing done in encoding (i.e., between the encoding operation and the retrieval cues). According to Tulving (1979), this idea is compatible with LOP because the recall of graphic, semantic or phonetic elements is superior when encoded by physical, phonetic or semantic characteristics, respectively. However, the adoption of an encoding type that is compatible with recall does not prevent the LOP effect; i.e., semantic (deeper) encoding causes an overall higher proportion of retained memory than more shallow types of encoding (Craik \& Tulving, 1975).

Lockhart and Craik (1990) introduced the term "robust encoding" to explain that levels of processing influence the transfer-appropriate processing in the sense that a more deeply encoded trait becomes accessible to more cues at the time of recall. Thus, Craik (2002) states that the idea of transfer-appropriate processing is complementary to LOP, i.e., that encoding and retrieval are integrated in such a way that the initial processes determine the qualitative nature of the trait encoded, and deeper encodings are associated with greater retrieval potential in an environment conducive to recall. For example, when a student is studying a particular concept, he/she seeks to establish multiple associations with it, building a broad and interconnected "semantic network." Thus, when retrieval is required (for example, during an examination), he/she will have a wider "range" of cues available to recall the content.

As Craik (2002) presented, one of the major contributions of the LOP framework is the understanding of recall as a process and an activity of the mind as opposed to structural ideas in which memory traces are entities that should be searched for and reactivated. As Tulving (2001) affirms, memory is not simply a reconstruction in which the subject picks up pieces of a mind puzzle and reconstructs the recollection; rather, it is pure construction, in which the subject must rebuild the episode, which is why the memory is so prone to error. This may explain the old adage that if you tell a lie often enough, it becomes truth.

Craik (2002) points out that deeper processing does not necessarily require more time than shallow processing. However, deeper processes require more attention (Treisman, 1964; Craik \& Byrd, 1982). Divided attention results in shallower encoding, but this relationship is modulated by the meaning of the stimulus and by the expertise (i.e., the degree of content knowledge) of the person doing the processing. A question was raised by an experiment by Vaz et al. (manuscript in preparation) that compared the effects of deep processing in recall of a list of words with no guided task at all and with a shallow guided task (open letters counting). The perceptual guided instruction led to a poorer performance as expected, but the semantically guided instruction produced the same level of performance as no instruction at all. These results are interpreted as a) the standard way of processing words is semantic; b) the perceptual task divides attention from meaning and thus decreases recall. Bellezza, Cheesman, and Reddy (1977) argued that after a certain amount of semantic processing (deep processing), additional semantic processing does not increase the probability of word retrieval. So, once the subject understood the meaning of the word, deep processing is not necessary. However, experiments show that there is a difference at the same LOP, for example, at the semantic processing one can check if a word fits on a phrase or appreciate it (Roediger \& Gallo, 2002). This latter issue can be appreciated under the heading of elaboration, further incorporated by Craik (2002).

Ekuni, Vaz, and Bueno (manuscript in preparation) carried out an experiment with healthy young subjects using LOP manipulation and perceptual manipulation (some words were written in colored ink). The results showed that the words deeply processed were better recalled than shallowly processed words - a typical LOP effect. It also showed a facilitation effect of perceptually manipulated words on free recall, but no interaction between type of processing and perceptual manipulation. These results suggest that perceptual aspects of a stimulus that distinguish it from others in the same set may have an auxiliary role in free recall of the set, but the key issue is the meaning of these stimuli, suggesting that the hierarchy of LOP is important.

With the advent of new technologies, Nyberg (2002) conducted a review in which levels of processing were analyzed in relation to neuroimaging and computed tomography (CT)-positron emission tomography (PET) scan studies were used to verify the correlation between these studies and the LOP framework. As previously stated, Craik and Lockhart (1972) argued that the memory trace is a consequence of processing during encoding; Nyberg (2002) states that according to the overlap of encoding-retrieval when information is recovered, the same brain area that was activated during encoding should be reactivated. Nyberg (2002) presented evidence suggesting that some brain regions that are activated during encoding are reactivated during retrieval. Thus, as in the study by Craik and Lockhart (1972), the memory trace depends on how the content was encoded.

\section{Neuroimage of LOP}

According to the LOP framework, the different levels of processing (shallow or deep) must be associated with different brain activity patterns, and deep processing must have more durable traces (Walla 
et al., 2001). Nyberg (2002) verified that activity in the prefrontal cortex and the medial temporal region is associated with deeper levels of processing and better performance on memory tests.

Kapur et al. (1994) conducted a study with PET scan to establish correlations between the activation of different cortical areas and the task used to encode the stimuli. They used two guided tasks for this: (a) detecting the presence or absence of the letter "a" (perceptual/shallow processing) and (b) categorizing the word as indicating something living or inanimate (semantic/deep processing). A greater activation of the lower left prefrontal cortex in the semantic tasks was seen, indicating involvement of this cortical area in semantic decision tasks.

\section{Criticism of the LOP framework}

Lockhart and Craik (1990) suggested two main types of criticism of the LOP framework: a) conceptual and methodological issues and b) more empirical issues, i.e., experimental support for hypotheses suggested by the LOP framework. Regarding the first, Baddeley (1978) and Eysenk (1978a) questioned the hierarchy of levels (from shallowest to deepest), suggesting that there is not a fixed series of processing stages. Baddeley (1978) also pointed out that there is not an independent method that researchers can use to measure how deep or shallow the processing is in an experiment. However, Lockhart and Craik $(1978,1990)$ claimed that the most important aspect is not the sequence of processing stages but the achieved analysis patterns. In accordance with Roediger and Gallo (2002), the term "levels of processing" is currently used more generally to emphasize the fact that the use of different types of processing during encoding provides different levels of memory performance.

Another criticism from Eysenk (1978b) is that LOP is not compatible with the transfer-appropriate processing (Morris et al., 1977) or encoding-specificity principle (Tulving \& Thomson, 1973) because the LOP framework does not makes references to retrieval conditions. As seen above, this type of criticism was responded to by incorporating the conditions of retrieval in the LOP framework.

Nelson (1977) criticized the LOP framework because, theoretically, repetition does not influence recall when considering the same level of processing, but his experiments showed that repetition at the phonemic level facilitates memory. During his experiment, three groups of subjects processed words at the phonemic level: a) one repetition of 12 items; b) two massed repetition; c) two spaced repetition. The massed and distributed repetition was better than one repetition. For Lockhart and Craik (1990), repetition itself does not facilitate recall, but there are qualitative types of reverberation that may influence memory. Although the second argument is solid, for repetition there is sufficient evidence that it does facilitate recall.

\section{Mnemonic strategies}

As mentioned earlier, wanting to remember something is not the most important factor in being able to remember something. In 1975, Craik and Tulving conducted an experiment in which subjects were paid for every word they could recall. Three blocks of 20 words were presented; for each block, the subject read the word and responded to a question based on the processing used: perceptual processing (for example, is the word printed in capital letters?), phonological processing (rhyme; for example, does the word rhyme with "feet"?); and semantic processing (category: for example, is the word a type of fruit?). For each type of processing, the experimenter set an amount to be paid. The words that were processed more deeply (categories) were recalled more often than those that were processed in a shallow way (perceptually, or using rhyme), even when the subjects received more money to recall words in the shallow group. Some subjects reported that they wanted to recall the words that were worth more but recalled more words that had been processed more deeply.

In a later work, Craik (2002) made a differentiation between depth and elaboration, although these processes are related. The former refers to the qualitative type of processing performed (levels-extension: from shallowest to deepest), i.e., basing processing on the physical, phonetic or semantic characteristics of the information. Elaboration refers to the degree to which each type of processing was enriched during encoding and it integrates the new item into already organized general knowledge structures or context cues, enabling the creation of cues that facilitate recovery. For example, identifying the category to which the stimulus belongs (dog-animal; freezer-object found in the kitchen) or establishing relationships with past events (associating "freezer" with the memory of the freezer in one's home) are elaboration strategies that facilitate the recall of these words because they enrich the stimulus to be remembered.

Regarding the strategy of creating a story around the content to be remembered, Bellezza et al. (1977) gave two groups of people lists of unrelated words. One group had to read the word and form a sentence, whereas the other group read the word and formed a coherent sentence related to a sentence created earlier, thus forming a story with the sentences. The group who formed the story recalled more words than the group who formed unrelated sentences. Why? Mandler (2002), in his organizational theory of memory, states that if a subject organizes ideas effectively during encoding, the information will probably be available at the time of recall. In addition, Einstein and Hunt (1980) argued that 
organization theory directs attention to the relationship between list items, whereas the LOP framework requires that the subject focus on items individually. However, when these two types of processing - organization and LOP - are used together, recall is positively affected. For Mandler (2002), LOP partially incorporates the basic processes of organization.

Certainly, when semantic processing is appropriate, it leads to a better recollection than attending only to nonsemantic aspects of the stimuli (Gardiner, 1974; Hyde \& Jenkins, 1969; Demb et al., 1995). As Bellezza et al. (1977) remind us, words are basically semantic units, thus requiring semantic memory to be recalled.

\section{Application of LOP manipulation in neuropsychological studies}

The manipulation of different levels of processing is widely used in neuropsychological studies of healthy individuals as well as in research with patients with specific pathologies. These studies often aim to answer questions about the levels of processing framework or to see how it behaves in certain situations and even for understanding the memory process as in the study by Sheridan and Reingold (in press). These authors used LOP manipulation with their new remember-know paradigm to counter the critics who claim that deep processing increases only "remember" but not "know" trials. They found that deep processing increased both "remember" and "know" proportions. LOP manipulation was very useful in this study to prove the authors' hypothesis. Other studies sought to understand the mnemonic process such as the study by Loaiza, McCabe, Youngblood, Rose and Myerson (2011). These authors used working memory and episodic memory tasks and found that LOP influences both immediate and delayed recall, which can help researchers understand some models of memory.

Hamann and Squire (1996) conducted a study using amnesic patients and a control group. In the study, the authors manipulated levels of processing to see if they affected priming (a type of implicit memory in which prior exposure to a stimulus influences the response to another stimulus [Squire \& Kandel, 2003]) in perceptual tasks. These authors observed that compared with the control group, amnesic patients did not exhibit LOP effects during priming tasks for completing words. Thus, this study with amnesic patients verified that LOP does have an effect on the priming of perceptual tasks.

In another study conducted with patients with unilateral medial temporal lobe epilepsy, LespinetNajib et al. (2004) investigated the role of the right and left temporal lobes in LOP tasks. The authors concluded that the right temporal lobe is more specialized in semantic processing because patients with right temporal lobe epilepsy showed deficits in the free-recall test phase of the study, which required semantic (deep) processing.

Toichi and Kami (2002) studied autistic patients with the LOP manipulation. Such studies aim to verify how LOP behaves in certain situations. In this study, the authors verified that there is no LOP effect in autism, and that the autistic subject's episodic memory performance was superior to that of the control group. Similar studies of patients with attention-deficit hyperactivity disorder (ADHD; Hale, Bookheimer, McGough, Phillips, \& McCracken, 2007) and dyslexia (Pernet, Valdois, Celsis, \& Démonet, 2006) can also be cited.

Troyer, Häfliger, Cadieux, and Craik (2006), in a study involving an elderly population, manipulated levels of processing for learning names and faces and concluded that deep processing facilitates the learning of new names, thus suggesting that this type of intervention coupled with other interventions can help elderly subjects learn new names.

\section{Final considerations}

Throughout nearly 40 years of existence, the original concept of Craik and Lockhart (1972) has undergone changes and evolution. The contribution of the LOP framework to the study of human memory cannot be dismissed. The greatest contributions, according to Lockhart and Craik (1990), resulted from studies that are more procedurally than structurally oriented, thus supporting the idea that memory is not stored in memory stores and that stores determine the success of retention. Such contributions consider remembering as a processing and as the LOP predict, the processing used during encoding stage is more important to remember, so memory is seen as pure construction (Tulving, 2001).

However, some questions remain unanswered. Roediger and Gallo (2002) pointed out some of these issues. For instance, why, even under conditions in which the subject knows that he/she will have to remember words, are there levels of processing effect? Why do variations among the same level of processing (for example, variations in semantic processing - check if a word fits on a phrase; say if you like or dislike the word) differentially affect memory? Why can subjects recall some words that are superficially processed? We can hypothesize about possible answers. For example, there may be variations on the same level of processing because different tasks require different degrees of cognitive effort. Thus, in a deep processing task, there may be tasks involving more cognitive effort than others; therefore, the item will be more deeply processed. In relation to the fact that subjects recall some words with shallow processing, it may be due to the fact that reading the word may automatically access its semantic meaning (Kirsner, 1973). However, to date, there are no satisfactory answers to these questions. 
The level of analysis of a particular stimulus depends upon several factors such as its meaning, the attention devoted to its perception, the intuitions and emotions of the subject concerning that particular stimulus, his/ her motivation, etc. (Kapur et al., 1994). But the LOP framework came to echo Bartlett's (1932) "effort after meaning" by the recalling mind.

\section{Acknowledgements}

This study was supported by the Fundação de Amparo à Pesquisa do Estado de São Paulo (FAPESP), the Associação Fundo de Incentivo à Pesquisa (AFIP) and the Conselho Nacional de Desenvolvimento Científico e Tecnológico (CNPq).

\section{References}

Atkinson, R. C., \& Shiffrin, R. M. (1968). Human memory: A proposed system and its control processes. In K.W. Spence (Eds.), The psychology of learning and motivation: Advances in research and theory. (Vol. 2, pp. 89-195). New York: Academic Press.

Baddeley, A. D. (1978). The trouble with levels: A reexamination of Craik and Lockhart's framework for memory research. Psychological Review, 85. 139-152.

Bartlett, F. C. (1932). Remembering: A study in experimental and social psychology. Cambridge, UK: Cambridge University Press.

Bellezza, F. S., Cheesman, F. L., \& Reddy, B. G. (1977). Organization and semantic elaboration in free recall. Journal of Experimental Psychology: Human Learning and Memory, 3, 539-550.

Bellezza, F. S., Richards, D. L., \& Geiselman, R. E. (1976). Semantic processing and organization in free recall. Memory and Cognition, 4, 415-421.

Challis, B. H., Velichkovsky, B. M., \& Craik, F. I. M. (1996). Levels-ofprocessing effects on a variety of memory tasks: New findings and theoretical implications. Consciousness and Cognition, 5, 142-164.

Craik, F. I. M. (2002). Levels of processing: Past, present and future? Memory, 10(5/6), 305-318.

Craik, F. I. M., \& Byrd, M. (1982). Aging and cognitive deficits: The role of attentional resources. In F. I. M. Craik \& S. E. Trehub (Eds.). Aging and cognitive processes (pp. 191-211). New York: Plenum.

Craik, F. I. M., \& Lockhart, R. S. (1972). Levels of processing: A framework for memory research. Journal of Verbal Learning and Verbal Behavior, 11, 671-684.

Craik, F. I. M., \& Tulving, E. (1975). Depth of processing and the retention of words in episodic memory. Journal of Experimental Psychology: General, 104, 268-294.

Demb, J. B., Desmond, J. E., Wagner, A. D., Vaidya, C. J., Glover, G. H., \& Gabrieli, J. D. E. (1995). Semantic encoding and retrieval in the left inferior prefrontal cortex. A functional MRI study of task-difficulty and process specificity. Journal of Neuroscience, 15, 5870-5878.

Einstein, G. O., \& Hunt, R. R. (1980). Levels of processing and organization: Additive effects of individual-item and relational processing. Journal of Experimental Psychology: Human Learning and Memory, 6(5), 588-598.

Ekuni, R., Vaz, L .J., \& Bueno, O. F. A. (n.d.). Effects of levels of processing on recall of perceptual manipulated words. Manuscript in preparation.

Eysenck, M.W. (1978a). Levels of processing: A critique. British Journal of Psychology, 69, 157-169.

Eysenck, M. W. (1978b). Levels of processing: A reply to Lockhart and Craik. British Journal of Psychology, 69, 177-178.

Gardiner, J. M. (1974). Levels of processing in word recognition and subsequent free recall. Journal of Experimental Psychology, 102, 101-105.

Hale, T. S., Bookheimer, S., McGough, J. J., Phillips, J. M., \& McCracken, J. T. (2007). Atypical brain activation during simple \& complex levels of processing in adults ADHD: An fMRI study.
Journal of Attention Disorders, 11(2), 125-140.

Hamann, S. B., \& Squire, L. R. (1996). Level-of-processing effects in word-completion priming: A neuropsychological study. Journal of Experimental Psychology: Learning, Memory and Cognition, 22(4), 933-947.

Hyde, T. S., \& Jenkins, J. J. (1969). Differential effects of incidental tasks on the organization of recall of a list of highly associated words. Journal of Experimental Psychology, 82, 472-481.

Kapur, S., Craik, F. I. M, Tulving, E., Wilson, A. A., Houle, S., \& Brown, G. M. (1994). Neuroanatomical correlates of encoding in episodic memory: Levels of processing effect. Proceedings of the National Academy of Sciences of the United States of America, 91, 2008-2011.

Kirsner, K. (1973). An analysis of the visual component in recognition memory for verbal stimuli. Memory \& Cognition, 1(4), 449-453.

Lespinet-Najib, V., N'Kaoua, B., Sauzéon, H., Bresson, C., Rougier, A., \& Claverie, B. (2004). Levels of processing with free and cued recall and unilateral temporal lobe epilepsy. Brain and Language, 89, 83-90.

Loaiza, V. M., McCabe, D. P., Youngblood, J. L., Rose, N. S., \& Myerson, J. (2011). The influence of levels of processing on recall from working memory and delayed recall tasks. Journal of Experimental Psychology: Learning, Memory and Cognition 37(5), 1258-1263.

Lockhart, R. S., \& Craik, F. I. M. (1978) Levels of processing: A reply to Eysenck. British Journal of Psychology, 69, 171-175.

Lockhart, R. S., \& Craik, F. I. M. (1990). Levels of processing: A retrospective commentary on a framework for memory research. Canadian Journal of Psychology, 44(1), 87-112.

Mandler, G. (2002). Organisation: What levels of processing are levels of. Memory, 10(5/6), 333-338.

Moscovitch, M., \& Craik, F. I. M. (1976). Depth of processing, retrieval cues, and uniqueness of encoding as factor in recall. Journal of Verbal Learning and Verbal Behavior, 15, 447-458.

Morris, C. D., Bransford, J. D., \& Franks, J. J. (1977). Levels of processing versus transfer-appropriate processing. Journal of Verbal Learning and Verbal Behavior, 16, 519-533.

Nelson, T. O. (1997). Repetition and depth of processing. Journal of Verbal Learning and Verbal Behavior, 16, 151-171.

Nyberg, L. (2002). Levels of processing: A view from functional brain imaging. Memory, 10(5/6), 345-348.

Pernet, C., Valdois, S., Celsis, P., \& Démonet, J. F. (2006). Lateral masking, levels of processing and stimulus category: A comparative study between normal and dyslexic readers. Neuropsychologia, 44, 2374-2385.

Richardson-Klavehn, A., Gardiner, J. M., \& Ramponi, C. (2002). Level of processing and the process-dissociation procedure: Elusiveness of null effects on estimates of automatic retrieval. Memory, 10(5/6), 349-364.

Roediger, H. L., III, \& Gallo, D. A. (2002). Levels of processing: Some unanswered questions. In: M. Naveh-Benjamin, M. Moscovitch, \& H. L. Roediger (Eds). Perspectives on human memory and cognitive aging: Essays in honour of Fergus Craik (pp. 28-47) New York: Psychology Press.

Roediger, H. L., III, Gallo, D. A., \& Geraci, L. (2002). Processing approaches to cognition: The impetus from the levels-of-processing framework. Memory, 10(5/6), 319-332.

Sheridan, H., \& Reingold, E. M. (in press). Levels of processing influences both recollection and familiarity: Evidence from a modified remember-know paradigm. Consciousness and Cognition doi:10.1016/j.concog.2011.09.022

Squire, L. R., \& Kandel, E. R. (2003). Memória: da mente às moléculas. São Paulo: ArtMed.

Toichi, M., \& Kamio, Y. (2002). Long-term memory and levels-ofprocessing in autism. Neuropsychology, 40, 964-969.

Treisman, A. (1964). Monitoring and storage of irrelevant messages in selective attention. Journal of Verbal Learning and Verbal Behavior, 3, 449-459.

Tulving, E. \& Thomson, D. M. (1973). Encoding specificity and retrieval process in episodic memory. Psychological Review 80, 352-373.

Tulving, E., (1979). Relation between encoding specificity and levels of processing. In L. S. Cermak \& F. I. M. Craik (Eds.), Levels of processing in human memory (pp. 405-428). Hillsdale, NJ: Erlbaum.

Tulving, E. (2001). Episodic memory and common sense: How far apart? Philosophical Transaction of Royal Society London B, 356, 1505-1515. 
Tulving, E. (2002). Does memory encoding exist? In M. NavehBenjamin, M. Moscovitch, \& H. L. Roediger, III (Eds.). Perspectives on human memory and cognitive aging: Essays in Honor of Fergus Craik (pp. 6-27). Philadelphia: Psychology Press. Vaz, L. J., Oliveira, L. G., Oliveira, M. G. M., Ruiz, A. M. N., Ekuni, R., Pompéia, S., \& Bueno, O. F. A. (n.d.). Levels-of-processing on facilitation of recall of semantically, phonetically, and perceptually distinctive words. Manuscript in preparation.

Walla, P., Hufnagl, B., Lindiger, G., Imhof, H, Deecke, L., \& Lang, W. (2001). Left temporal and temporoparietal brain activity depends on depth of word encoding: A magnetoencephalographic study in healthy young subjects. NeuroImage, 13, 402-409. 